PERANCANGAN JARINGAN KOMPUTER BERBASIS MIKROTIK

Oleh:

Zaki Amanda Naufal ${ }^{1}$,YuhendriPutra ${ }^{2}$

(Program Studi Teknik Informatika Fakultas Ilmu Komputer Universitas Lancang Kuning)

E-mail:1'zakyamandanaufal623@gmail.com, ${ }^{2}$ yuhendri204@gmail.com,

\begin{abstract}
Abstrak
Jaringan komputer adalah system yang terdiri dari beberapa komputer yang dirancang untuk dapat berbagi data,informasi,dan sumber daya.Tujuan dari jaringan komputer adalah agar setiap bagian dari jaringan komputer dapat meminta dan menyediakan layanan informasi dan data.Pihak yang meminta atau menerima layanan disebut dengan klien dan siapa yang mengirim atau mengirim layanan disebut dengan server.Di Departemen Pengajaran Fakultas komputer mendesain menggunakan topologi jaringan tipe bintang yang telah ada dilakukan agar pengembangan beban jarigan tidak terpusat pada perangkat keras saklar.Dalam desain jaringan dilakukan mikrotik adalah perangkat jaringan yang berfungsi sebagai gateway serta router.Dalam konfigurasi alamat IP menggunakan DHCP Server untuk memfasilitasi pemasangan komputer baru di jaringan.Komputer baru tidak perlu dikonfigurasi secara manual,itu akan secara otomatis terhubung ke jaringan
\end{abstract}

Kata kunci : jaringan komputer, mikrotik, gigabit switch

\title{
Pendahuluan
}

Dengan adanya perkembangan teknologi informasi yang semakin pesat ditunjang berbagai penemuan dan inovasi telah membawa banyak perubahan bagi kehidupan manusia. Hal tersebut juga menyebabkan munculnya kemajuan dan kecanggihan teknologi beserta perangkat kerasnya. Secara langsung ataupun tidak langsung, teknologi informasi telah menjadi bagian penting dalam berbagai aspek kehidupan manusia karena kemudahan pekerjaan manusia dengan adanya dukungan dari teknologi informasi.Teknologi informasi memudahkan manusia untuk berbagi informasi ataupun mencari informasi. Hal tersebut dapat dilihat dari semakin berkembangnya teknologi internet dan jaringan. Sekarang ini internet merupakan suatu kebutuhan dalam berbagi informasi ataupun mencari informasi.Jaringan komputer adalah sebuah sistem yang terdiri dari beberapa komputer yang didesain untuk dapat berbagi data, informasi, dan sumber daya. Tujuan dari jaringan komputer adalah setiap bagian dari jaringan komputer dapat meminta dan memberikan layanan informasi dan data.Pihak yang meminta atau menerima layanan disebut dengan klien dan yang memberikan atau mengirim layanan disebut dengan server.Sebuah perusahaan atau instansi dalam proses bisnisnya membutuhkan komputer untuk mengerjakan berbagai pekerjaan kompleks yang berkaitan dengan komputasi dan pengolahan data. Setiap komputer pada tiap bagian membutuhkan adanya interkoneksi dengan komputer pada bagian yang lain, sehingga membuat interkoneksi antar komputer pada sebuah perusahaan atau instansi adalah menjadi hal penting untuk meningkatkan produktifitas kerja pada instansi tersebut.Bagian Pengajaran Fakultas Komputer adalah salah satu bentuk organisasi yang membutuhkan interkoneksi komputer berupa jaringan komputer yang handal. Berbagai pekerjaan terkait dengan pengelolaan administrasi dan pelayanan kepada mahasiswa membutuhkan jaringan komputer untuk pelaksanaannya. Kondisi yang ada saat ini Bagian Pengajaran Fakultas Komputer memiliki kendala dalam hal mengakses internet. Hal tersebut di atas disebabkan karena belum adanya rancangan topologi jaringan komputer yang ideal pada Bagian Pengajaran Fakultas Informatika. 
Dengan perancangan topologi jaringan komputer yang baik dan handal akan membantu staf pengajaran dan mahasiswa di lingkungan Fakultas Komputer dalam mengakses internet untuk mencari informasi dan berbagi sumber daya informasi dengan komputer yang lain.Untuk membatasi ruang lingkup pada penelitian ini maka diberikan batasan masalah, diantaranya adalah sebagai berikut :

$\square$ Jaringan komputer yang dirancang hanya meliputi lingkungan Bagian Pengajaran Fakultas Informatika.

$\square$ Jaringan komputer dirancang dengan menggunakan Mikrotik.

Dalam penelitian yang dilakukan ini tujuan yang ingin dicapai antara lain sebagai berikut:

$\square$ Merancang sebuah jaringan komputer dengan berbasiskan Mikrotik Router di Bagian Pengajaran Fakultas Informatika.

Merancang jaringan komputer dengan topologi yang terbaik sehingga dapat diterapkan di Bagian Pengajaran Fakultas Informatika.

\section{Definisi Jaringan Komputer}

Menurut Forouzan (2008) Jaringan adalah seperangkat devices (biasanya disebut sebagai nodes) yang dihubungkan melalui communication links. Pada dasarnya tujuan dari pembuatan jaringan adalah untuk:

1. Dapat menghemat hardware seperti

berbagi pemakaian printer dan CPU.

2. Melakukan komunikasi, contohnya surat

elektronik, instant messaging, chatting.

3. Mendapatkan akses informasi dengan

cepat, contohnya web browsing.

4. Melakukan sharing data.

Jaringan komputer adalah jaringan telekomunikasi yang memungkinkan antar komputer untuk saling bertukar data.Tujuan dari jaringan komputer adalah agar dapat mencapai tujuannya, setiap bagian dari jaringan komputer dapat meminta dan memberikan layanan (service). Pihak yang meminta atau menerima layanan disebut klien (client) dan yang memberikan atau mengirim layanan disebut server. Desain ini disebut dengan sistem client-server, dan digunakan pada hampir seluruh aplikasi jaringan komputer (Wikipedia, 2016).Dua buah komputer yang masingmasing memiliki sebuah kartu jaringan, kemudian dihubungkan melalui kabel maupun nirkabel sebagai medium transmisi data, dan terdapat perangkat lunak sistem operasi jaringan akan membentuk sebuah jaringan komputer.

\section{Topologi Jaringan}

Topologi jaringan komputer adalah infrastruktur fisik jaringan komputer yang digunakan untuk mengimplementasikan Local Area Network (LAN).Topologi yang digunakan untuk jaringan komputer yang akan dibahas adalah Topologi Bintang.

\section{Pengertian Topologi Bintang}

Topologi bintang adalah topologi jaringan komputer yang menggunakan concentrator (hub/switch) sebagai pengatur paket data.Topologi bintang memiliki kontrol yang terpusat. Semua link harus melewati pusat yang menyalurkan data tersebut ke semua simpul atau client yang dipilihnya. Simpul pusat dinamakan stasiun primer atau server dan lainnya dinamakan stasiun sekunder atau client server.Setelah hubungan jaringan dimulai oleh server maka setiap client server sewaktu waktu dapat menggunakan hubungan jaringan tersebut tanpa menunggu perintah dari server.

\section{Kelebihan :}


Kerusakan pada satu saluran hanya akan memengaruhi jaringan pada saluran tersebut dan station yang terpaut.

Tingkat keamanan termasuk tinggi.

Tahan terhadap lalu lintas jaringan yang sibuk.

Kemudahan deteksi dan isolasi kesalahan/kerusakan pengelolaan jaringan.

\section{Kelemahan:}

Switch dan Hub menjadi elemen kritis karena kontrol terpusat. Jaringan tergantung pada terminal pusat.

Biaya jaringan lebih mahal

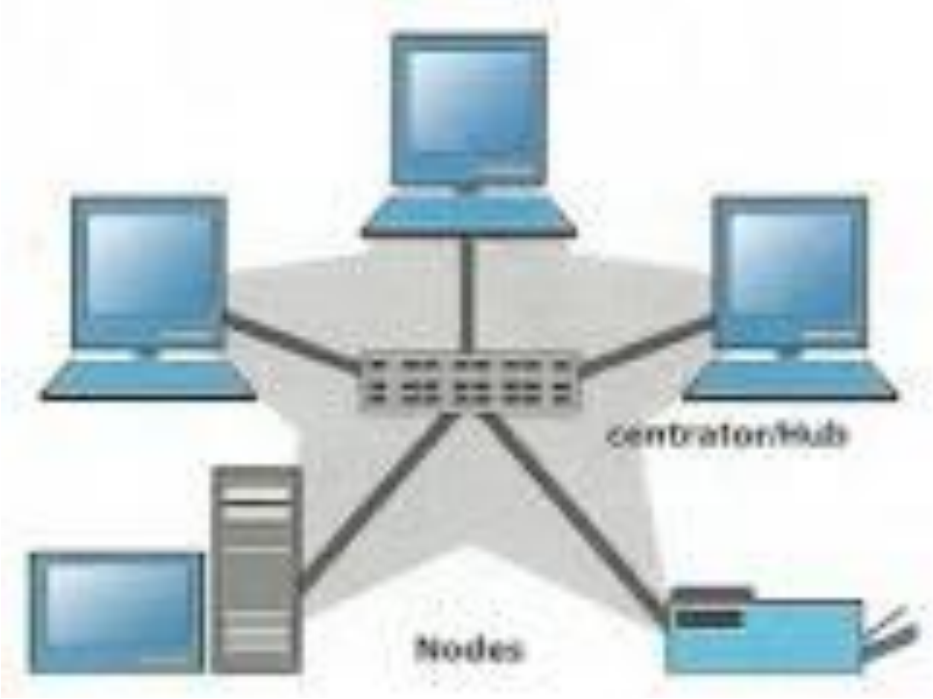

Gambar Topologi Bintang

\section{Router}

Router adalah perangkat yang akan melewatkan paket IP dari suatu jaringan ke jaringan yang lain, menggunakan metode addressing dan protocol tertentu untuk melewatkan paket data tersebut.Router memiliki kemampuan melewatkan paket IP dari satu jaringan ke jaringan lain yang mungkin memiliki banyak jalur diantara keduanya.Router yang saling terhubung dalam jaringan internet turut serta dalam sebuah algoritma routing terdistribusi untuk menentukan jalur terbaik yang dilalui paket IP dari system ke system lain.Proses routingdilakukan secara hop by hop. IP tidak mengetahui jalur keseluruhan menuju tujuan setiap paket. IP routing hanya menyediakan IP address dari router berikutnya yang menurutnya lebih dekat ke host tujuan. 


\section{Mikrotik}

Mikrotik adalah perangkat jaringan yang memiliki sistem operasi dan perangkat lunak yang dapat digunakan untuk menjadikan komputer manjadi router network yang handal, mencakup berbagai fitur yang dibuat untuk ip network dan jaringan wireless, cocok digunakan oleh ISP dan provider hotspot.

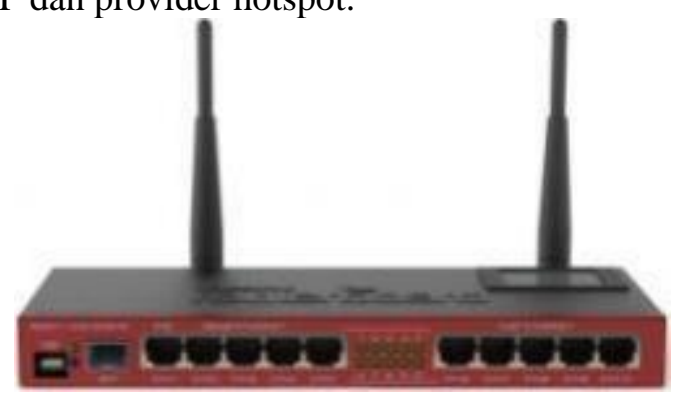

Mikrotik dalam distribusi pemasarannya ada dua jenis yaitu:

$\square$ Mikrotik RouterOSTM, versi MikroTik dalam bentuk perangkat lunak yang dapat diinstal pada komputer rumahan (PC) melalui CD. File image MikroTik RouterOS dapat diunduh dari website resmi MikroTik, www.mikrotik.com.Namun, file image ini merupakan versi trial MikroTik yang hanya dapat digunakan dalam waktu 24 jam saja.Untuk dapat menggunakannya secara full time, harus membeli lisensi key dengan catatan satu lisensi hanya untuk satu harddisk.

$\checkmark$ Built In Hardware adalah Mikrotik dalam bentuk perangkat keras yang khusus dikemas dalam board router yang didalamnya sudah terinstal Mikrotik Router Operating System.

\section{Kabel Jaringan}

Ada beberapa kabel yang digunakan sebagai media penghantar data dalam sebuah jaringan, diantaranya adalah kabel koaksial (Coaxcial / Bayonet Neil Concelman "BNC"), Twisted Pair ( UTP dan STP ) dan Fiber Optic.

\section{METODE PENELITIAN}

Dalam penelitian ini menggunakan beberapa metode diantaranya sebagai berikut: $\square$ Analisis, penulis melakukan analisis permasalahan yang terjadi dan melihat kebutuhan dari analisa yang akan dilakukan. Dimulai dengan melakukan analisis kebutuhan secara umum.

$\square$ Studi literatur, penulis mencari literatur untuk mendapatkan informasi-informasi yang berhubungan dengan permasalahan dan perancangan jaringan komputer melalui buku dan karya ilmiah sebelumnya.

$\square$ Pengamatan/Observasi, cara ini dilakukan untuk mengamati secara langsung di Bagian Pengajaran Fakultas Komputer.

$\square$ Analisa Kebutuhan, dari hasil pengamatan akan ditemukan permasalahan yang ada dan akan bisa dibuat analisa kebutuhan sistem jaringan komputer sehingga dari analisa ini dapat menjadi bahan dalam perancangan sistem jaringan komputer yang baik di Bagian Pengajaran Fakultas Informatika.

$\square$ Perancangan Sistem, penulis kemudian merancang hasil analisa dalam bentuk perancangan sistem dan topologi jaringan komputer di Bagian Pengajaran Fakultas Komputer. 


\section{ANALISIS KEBUTUHAN SISTEM}

Dalam melakukan penelitan ini penulis melakukan analisis kebutuhan perangkat keras dan perangkat lunak.

\section{Analisis Perangkat Keras (Hardware)}

Perangkat keras adalah komponen utama dalam sebuah sistem komputer. Perangkat keras yang digunakan untuk membuat dan melakukan uji coba adalah perangkat keras dengan satu unit komputer yang memiliki spesifikasi minimum sebagai berikut:

Prosesor Intel Pentium Dual Core

RAM (Random Access Memory) 2 GB

VGA (Video Graphic Adapter) dengan dual output

Masukan berupa mouse dan keyboard

Keluaran berupa dua monitor

LAN Card dengan RJ-45 Jack

Wireless LAN Card

Keluaran berupa printer

Media penyimpanan Hardisk dengan kapasitas 80 GB

\section{Analisis Perangkat Lunak (Software)}

Selain perangkat keras, sisi perangkat lunak juga salah satu faktor yang dibutuhkan dalam perancangan sistem.Perangkat lunak yang digunakan adalah:

$\square$ Sistem Operasi Microsoft Windows 7 Ultimate

VirtualBox

Mikrotik RouterOS

Winbox

Aplikasi browser Mozilla Firefox

\section{Analisis Sistem Jaringan Komputer}

Infrastruktur jaringan di Fakultas Informatika sepertinya masih mengalami kendala yang cukup besar, terbukti dari hasil pengamatan yang dilakukan.Dari beberapa komputer yang terhubung ke jaringan masih terdapat komputer yang sering putus koneksinya sehingga tidak terhubung ke jaringan yang dapat mengganggu pelayanan kepada mahasiswa. Selain jaringan lewat kabel, jaringan wireless di Fakultas Teknik juga memiliki kendala yaitu adanya batasan beban pengguna. Ketika pengguna jaringan wireless cukup banyak akan membuat jaringan menjadi down.Hal tersebut di atas disebabkan infrastruktur jaringan Fakultas Teknik saat ini belum didukung dengan perangkat keras jaringan dengan kemampuan yang tinggi.Sehingga ketika beban jaringan besar sistem akan mengalami lag atau lambat dalam request melalui jaringan komputer.Perangkat jaringan saat ini juga akan mengalami overload ketika pemakaian jaringan komputer melebihi kemampuan perangkat yang ada. Efek terbesar dari overload jaringan yaitu dapat mengakibatkan jaringan komputer menjadi down.Dalam membangun jaringan komputer yang ideal akan membutuhkan biaya pengadaan infrastruktur yang cukup besar. Untuk dapat didapatkan biaya yang lebih efisien sebelum membangun infrastruktur harus dilakukan perancangan jaringan komputer yang tepat agar biaya yang dikeluarkan tidak terlalu besar. 
Berikut ini adalah gambaran jaringan komputer yang sudah ada di Fakultas Informatika

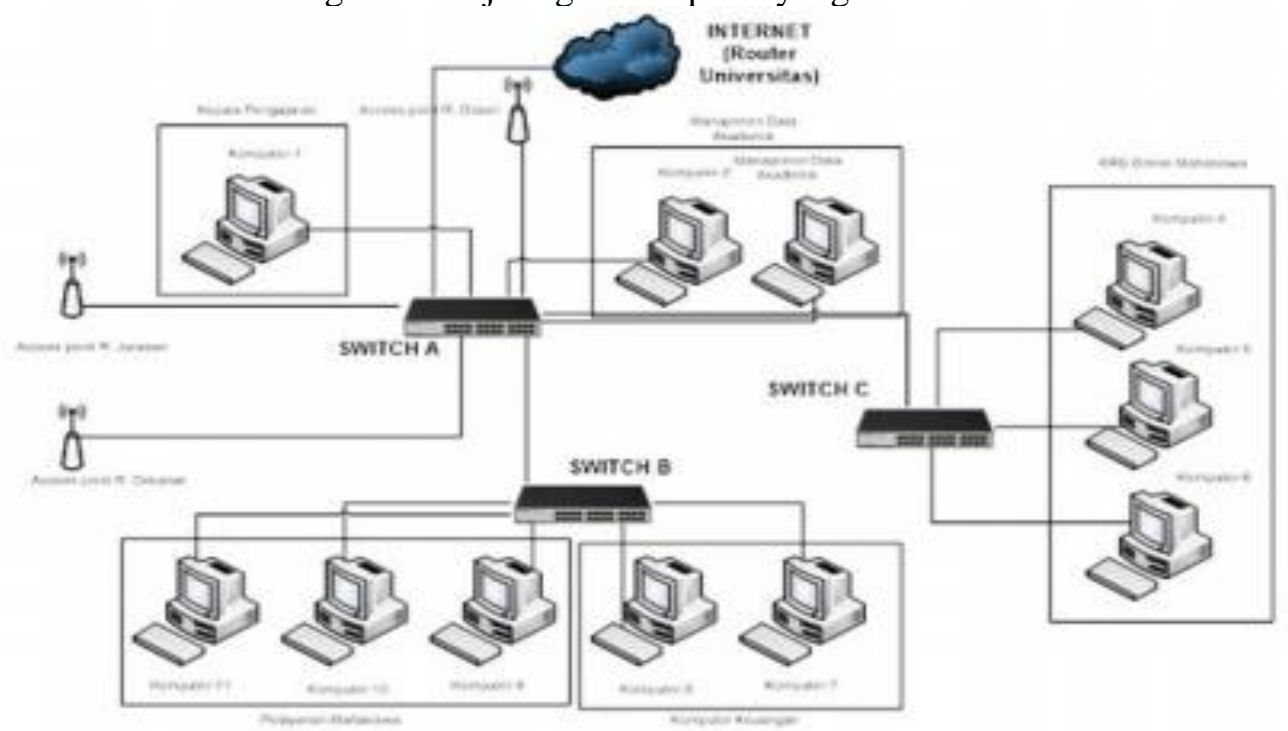

Dari gambar di atas dapat dilihat bahwa jaringan komputer yang ada sekarang memiliki beberapa kelemahan yaitu:

$\checkmark$ Jaringan komputer di Fakultas Komputer belum memiliki perangkat Router

$\square$ Beban jaringan terbesar ada pada perangkat Switch A sehingga switch A akan sering terjadi kondisi Hang.Karena switch biasa memiliki keterbatasan beban lalu lintas jaringan.

Jaringan komputer di Fakultas Komputer belum memiliki klasifikasi subjaringan.

Berdasarkan hasil pengamatan yang dilakukan terhadap sistem jaringan komputer yang ada pada Bagian Pengajaran Fakultas Informatika maka penulis melakukan perancangan jaringan komputer yang dimulai dari penentuan topologi jaringan, perangkat keras yang dibutuhkan, desain jaringan lokal, desain gateway internet dan yang terakhir penulis melakukan konfigurasi jaringan untuk memastikan jaringan yang dibangun dapat menghubungkan semua komputer dengan baik dan terhubung ke jaringan internet global.

\section{Perancangan Topologi Jaringan}

Untuk mendapatkan kemampuan jaringan komputer yang tinggi perlu dirancang topologi jaringan yang baik sejak awal dibangunnya jaringan komputer pada unit tersebut. Topologi akan menentukan kemampuan perangkat keras jaringan dalam melayani arus data yang melewati jaringan. Karena adanya penumpukan arus data pada perangkat keras juga dapat menimbulkan permasalahan pada jaringan. Jaringan akan menjadi down dan perlu dilakukan reboot ulang pada perangkat keras jaringan seperti switch dan access point.Dalam perancangan yang akan dibuat penulis menggunakan topologi jaringan model bintang (star) karena topologi ini memiliki kelebihan diantara topologi yang lainnya yaitu jika salah satu komputer mengalami masalah, jaringan pada topologi ini masih dapat berjalan dan tidak mempengaruhi komputer lainnya.

Tingkat keamanan dapat dibilang cukup baik daripada topologi yang lain.Kemudahan deteksi masalah cukup mudah bila terjadi kerusakan pada jaringan. Selain itu pada topologi star, setiap komputer memiliki akses dengan bandwidth penuh dari Local Area Network (LAN). Jaringan Komputer pada Bagian Pengajaran Fakultas Informatika setelah dilakukan pengamatan perlu dibuat beberapa subjaringan karena memiliki beberapa divisi yang terbagi berdasarkan kebutuhan dan klasifikasi pelayanan.Untuk mendapatkan jaringan komputer yang lebih handal, maka penulis melakukan pengembangan dari topologi star dengan memecah beberapa jaringan lokal menjadi beberapa subjaringan agar setiap divisi di Fakultas Teknik dapat memiliki jaringan komputer dengan range IPAddress private. IP Address merupakan identitas komputer di jaringan yang membedakan antara satu komputer dengan komputer yang lainnya.Dengan memecah jaringan menjadi subjaringan berdasarkan divisi penggunaan komputer juga dapat 
mengurangi beban perangkat keras jaringan seperti switch dan router.Di bawah ini dapatdillihat desain awal dari topologi jaringan yang penulis akan rancang.

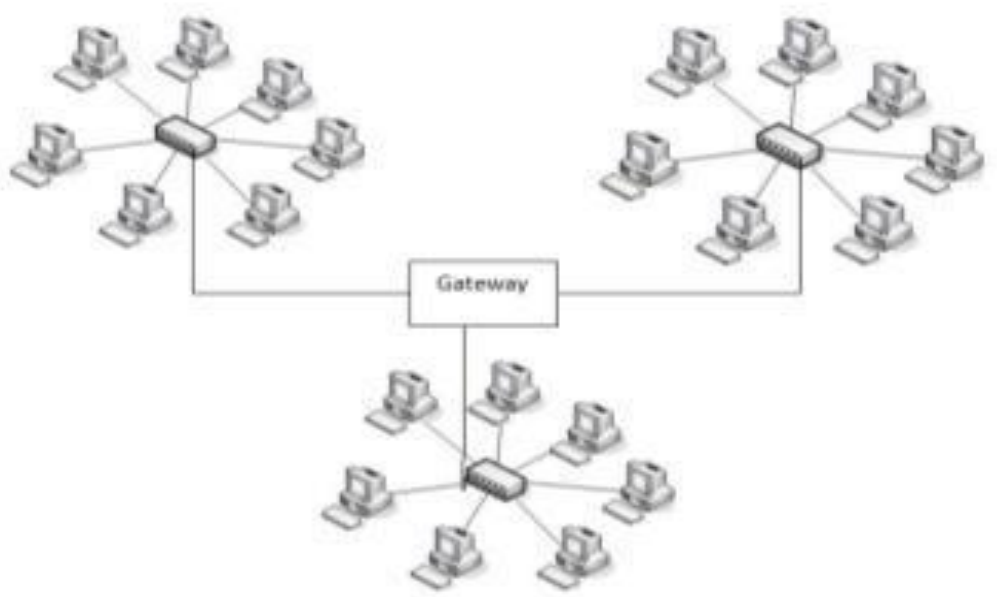

Gambar Topologi Star di Fakultas Komputer

Di pasaran perangkat jaringan sendiri memiliki berbagai banyak merek dan spefisikasi.Dalam perancangan jaringan di Fakultas Komputer membutuhkan perangkat jaringan antara lain, mikrotik router, gigabitswitch dengan 24 port, access point, dan kabel jaringan (UTP).

\section{Perangkat Keras yang Dibutuhkan}

Diperlukan perangkat jaringan dengan spesifikasi memadai untuk membangun jaringan komputer yang handal. Mikrotik router akan digunakan sebagai media sentral atau gateway yang akan menghubungkan antar subjaringan pada jaringan lokal. Mikrotik router akan menjadi perangkat jaringan inti yang mangatur routing dan pengalamatan IP Address pada jaringan.Dalam perancangan jaringan komputer Fakultas Komputer digunakan kabel UTP jenis Cat 5e. Kabel jenis ini dipilih karena dengan harga yang relatif murah kemampuan kabel ini dapat melakukan transfer data dengan kecepatan maksimal 1 Gbps. 


\section{Desain Jaringan Lokal}

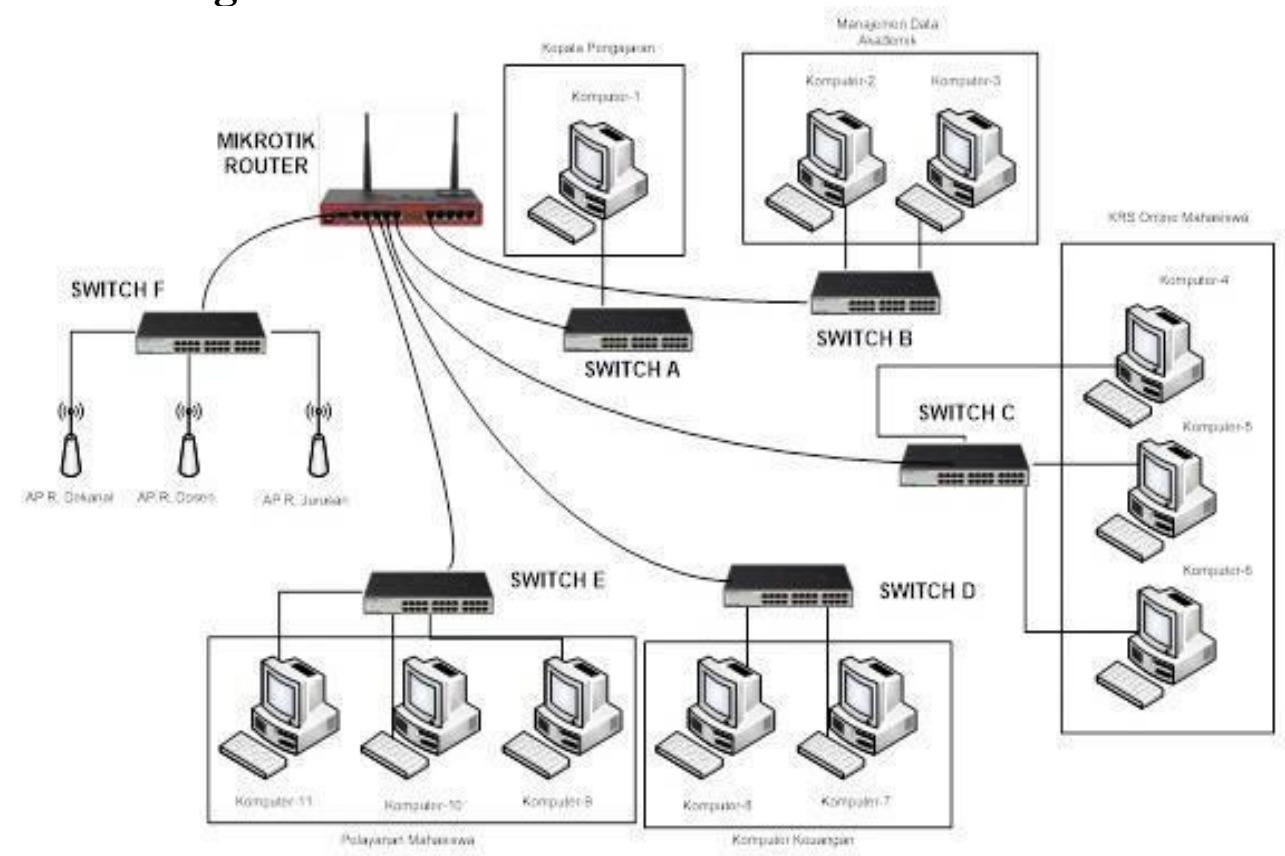

Pada desain jaringan di atas membutuhkan perangkat jaringan komputer sebagai berikut :

\begin{tabular}{|l|l|l|}
\hline \multicolumn{1}{|c|}{$\begin{array}{c}\text { Nama } \\
\text { Perangkat }\end{array}$} & \multicolumn{1}{|c|}{ Spesifikasi } & Jumlah \\
\hline Mikrotik Router & $\begin{array}{l}\text { RB2011-UAS- } \\
\text { 2HND-IN }\end{array}$ & 1 unit \\
\hline Switch 24 Port & $\begin{array}{l}\text { Gigabit Switch } \\
10 / 100 / 1000 \mathrm{Mbps}\end{array}$ & 7 unit \\
\hline Kabel UTP & CAT-5e Standar & 1 box \\
\hline Access Point & $\begin{array}{l}\text { Wifi } \\
802.11 \text { b/g/n }\end{array}$ & 1 box \\
\hline Jack RJ45 & CAT-5e RJ45 Jack & \\
\hline
\end{tabular}

Rancangan desain jaringan komputer yang baru menitikberatkan pada penambahan perangkat berupa router pada sentral jaringan. Router selain menjadi sentral jaringan juga menjadi perangkat yang menjadi manajemen pembagi bandwith pada jaringan.Jaringan dirancang dengan melakukan klasifikasi jaringan berdasarkan subjaringan yang ada, sebagai contoh komputer-komputer yang menangani bagian keuangan tidak akan tergabung dalam jaringan komputer untuk hotspot. Dengan metode ini diharapkan setiap jaringan akan memiliki beban lalu lintas jaringan sesuai dengan kapasitasnya. Berbeda dengan jaringan komputer yang ada sebelumnya,beban jaringan akan menjadi cukup besar karena seluruh komputer yang terhubung ke jaringan akan menerima broadcast setiap ada komputer yang terhubung. Untuk lebih mengoptimalkan kinerja jaringan pada seluruh switch menggunakan switch dengan jenis Gigabit switch yang mendukung bandwith sebesar $1 \mathrm{Gbps}$, dan dipilih switch dengan 24 port untuk mengakomodir penambahan komputer atau host pada jaringan.

\section{Desain Gateway Internet}

Pada desain jaringan lokal belum terlihat interkoneksi jaringan dengan jaringan internet.

Komputer pada jaringan lokal belum dapat terhubung ke internet. Untuk terhubung ke jaringan internet global rancangan desain jaringan yang baru harus dihubungkan dengan penyedia jasa internet (ISP). Hanya membutuhkan minimal satu line ISP yang dihubungkan ke perangkat mikrotik, maka jaringan lokal di Fakultas Komputer akan dapat menyambung ke jaringan internet global.Di Universitas Lancang Kuning jaringan internet terpusat di data center UPT 
Siskom yang bersumber dari dua provider yaitu Telkom dan SatNet. Rancangan jaringan komputer baru di Fakultas Teknik memerlukan jalur internet dari data center UPT Siskom agar dapat mempercepat akses ke dalam seluruh sistem informasi lokal di lingkungan Universitas Janabadra. Pada rancangan jaringan komputer yang baru penulis juga menambahkan opsional jalur internet lain yang bersumber dari provider lain selain yang sudah dilanggan oleh Universitas Janabadra. Jalur ini disarankan agar menjadi backup internet ketika jalur internet yang utama sedang off atau down.Berikut ini desain jalur internet untuk Fakultas Komputer :

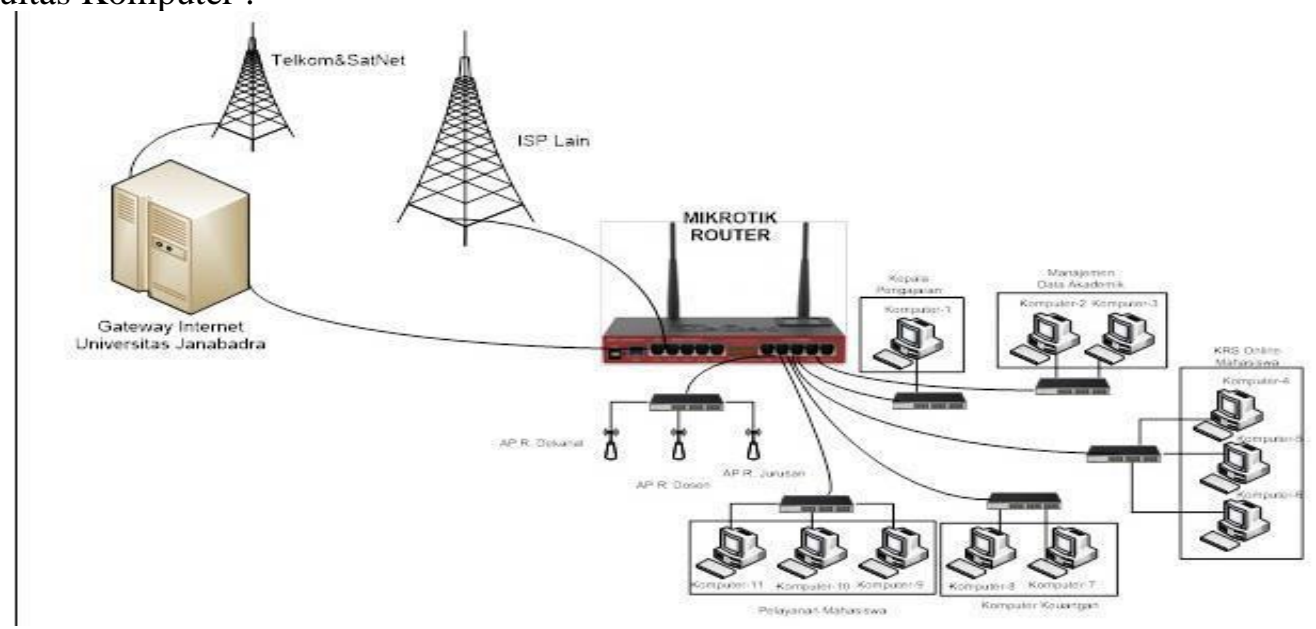

\section{Konfigurasi Jaringan}

\section{Pembagian Sub Jaringan}

Jaringan dibagi dan dipecah menjadi beberapa sub jaringan untuk mengurangi beban perangkat keras jaringan dan untuk memberikan jaringan privat pada tiap sub jaringan.

Pembagian dari jaringan yang baru adalah sebagai berikut:

$\square$ Sub Jaringan Kantor Kepala

Pengajaran

$\square$ Sub Jaringan Bagian Manajemen

Data Akademik

\section{Sub Jaringan Bagian Keuangan}

Sub Jaringan Bagian Pelayanan

Mahasiswa

Sub Jaringan Bagian KRS Mandiri

Sub Jaringan Hotspot

\section{Pemberian Alamat IP Address Sub Jaringan}

Pengaturan IP Address penting untuk dilakukan karena setiap sub jaringan nantinya akan memiliki IP Address privat sehingga tidak akan terjadi konflik antar komputer pada jaringan. Berikut daftar konfigurasi IP Address yang dibuat:

Sub Jaringan Kantor Kepala Pengajaran Menggunakan IP Address range: 192.168.0.1 - 192.168.0.254

$\square$ Sub Jaringan Bagian Manajemen Data Akademik

Menggunakan IP Address range: 192.168.1.1 - 192.168.1.254 
Sub Jaringan Bagian KeuanganMenggunakan IP Address range:

192.168.3.1 - 192.168.3.254

Sub Jaringan Bagian Pelayanan Mahasiswa

Menggunakan IP Address range:

192.168.4.1 - 192.168.4.254

$\square$ Sub Jaringan Bagian KRS Mandiri Menggunakan IP Address range:

192.168.5.1 - 192.168.5.254

$\square$ Sub Jaringan Hotspot Menggunakan IP Address range:

192.168.6.1 - 192.168.6.254

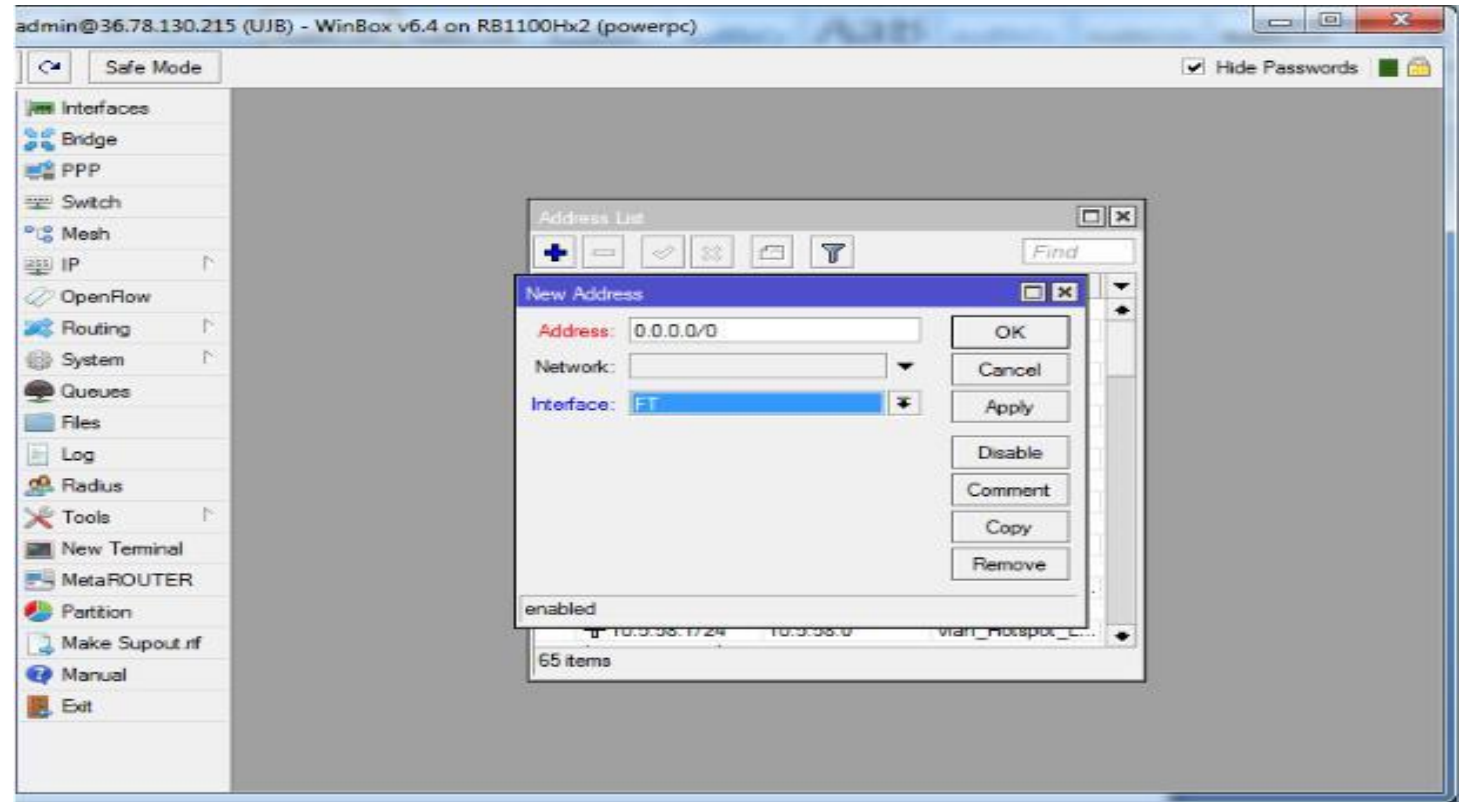

Konfigurasi IP Address pada Mikrotik

\section{Pembuatan Server DHCP Mikrotik}

Mikrotik adalah perangkat jaringan yang menjadi gateway sekaligus router. Di dalam sistem operasi mikrotik terdapat manajemen untuk pengaturan DHCP Server sehingga mempermudah instalasi komputer baru pada jaringan. Komputer baru tidak perlu dilakukan konfigurasi secara manual atau statis pada alamat internetnya secara otomatis akan terhubung ke jaringan.

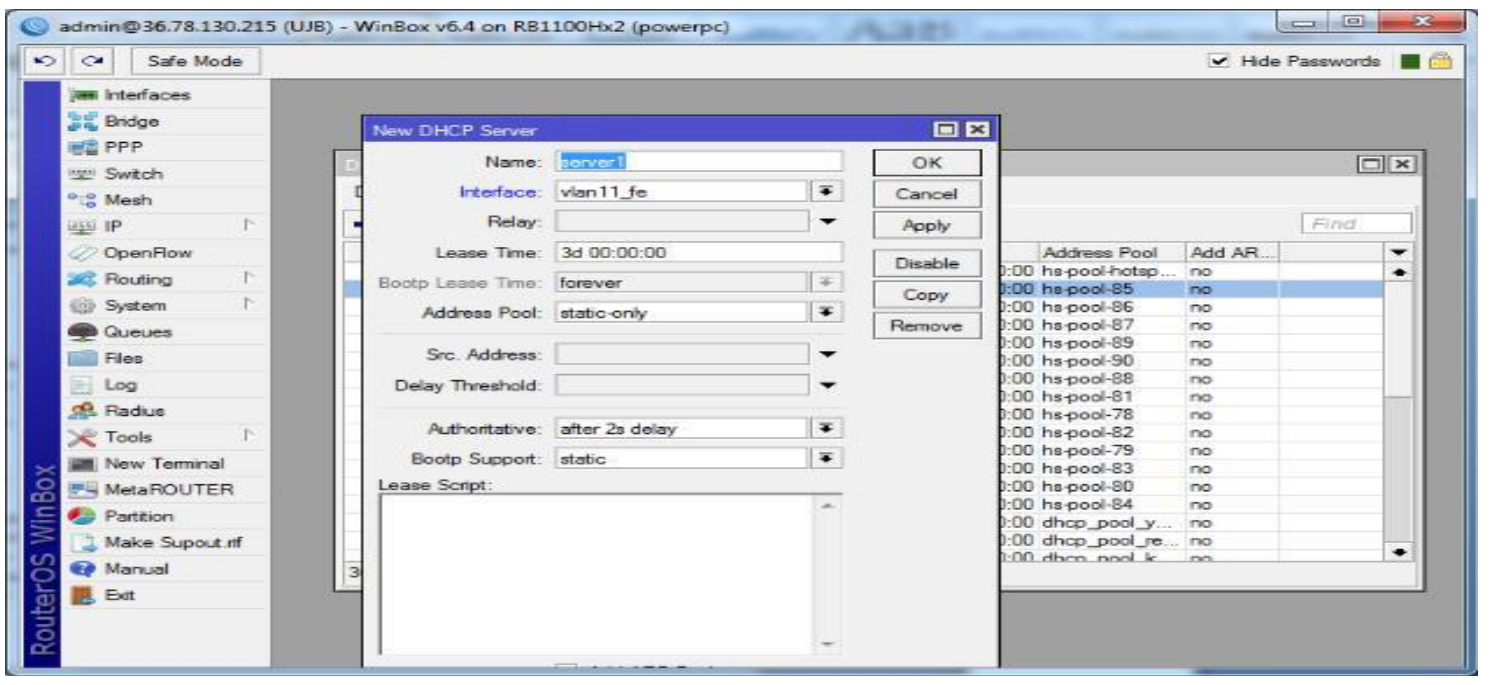


DHCP Server adalah solusi untuk menjadikan sebuah jaringan komputer mudah dalam pengembangan jaringan tersebut.Administrator jaringan atau teknisi tidak perlu melakukan pengaturan pada jaringan untuk menambah host atau komputer baru. 


\section{KESIMPULAN}

Dalam penelitian yang dilakukan

penulis dapat mengambil beberapa

kesimpulan, antara lain:

1. Pada Bagian Pengajaran Fakultas Komputer menggunakan topologi jaringan jenis bintang yang telah dilakukan pengembangan agar beban jaringan tidak terpusat pada perangkat keras switch.

2. Mikrotik adalah perangkat jaringan yang menjadi gateway sekaligus router.

3. DHCP Server mempermudah instalasi komputer baru pada jaringan. Komputer baru tidak perlu dilakukan konfigurasi secara manual, secara otomatis akan terhubung ke jaringan. 


\section{DAFTAR PUSTAKA}

1.Pengembangan Sistem Keamanan Jaringan Menggunakan Rumusan Snort Rule (Hids) untuk Mendeteksi Serangan Nmap (Dosen Unilak bapak Pandu Putra Pratama)

2.Anonim,

https://en.wikipedia.org/wiki/Local_ar

ea_network diakses pada Juni 2016

3.Anonim,

https://en.wikipedia.org/wiki/Compute

r_network diakses pada Juni 2016

4.Anonim, http://www.jogjabolic.com diakses

pada Juni 2016

5.Forouzan, Behrouz A. (2008). Data Communications and Networking 4th

ed.New York: McGraw-Hill.Sugeng, Winarno. (2010).

6.Jaringan Komputer dengan TCP/IP. Bandung:Modula

Towidjojo, R., 2012,

7.Mikrotik Kung Fu : Kitab 1. Jakarta: Jasakom

Towidjojo, R., 2013,

8.Mikrotik Kung Fu : Kitab 2. Jakarta: Jasakom Towidjojo, Rendra. 2012.

9.Konsep \& Implementasi Routing dengan Router Mikrotik : 100\% Connected. Jakarta:

Jasakom.Wagito. Jaringan Komputer Teori dan Implementasi Berbasis Linux. Yogyakarta:

Penerbit Gava Media,

2005

10.Aditya,A. N. (2011). Mahir Membuat

Jaringan Komputer.Bandung: Dunia

Komputer.

11.Badrul, Sugiarto, Wahyudi, \&

Suprayogi. (2012). Teknik Komputer

Jaringan Seri B (Sistem Operasi

Jaringan). Jakarta Timur: Inti Prima

Promosindo.

12.Daryanto. (2010). Teknik Jaringan

Komputer. Bandung: Alfabeta.

13.http://mikrotik.co.id/. (n.d.).

Retrieved April senin, 2016, from

http://mikrotik.co.id/:

http://mikrotik.co.id/

14.Pustakaraya. Purbo, O. W. (2006). 
Internet Wireless dan Hotspot. Jakarta:

Elex Media Komputindo.

15.Riadi, I. (2011). Optimalisasi

Keamanan Jaringan Menggunakan

Pemfilteran Aplikasi Berbasis Mikrotik.

JUSI Vol. 1, No. $1,74$. 